\title{
Wet chemistry route for the decoration of carbon nanotubes with iron oxide nanoparticles for gas sensing
}

\author{
Hussam M. Elnabawy ${ }^{1}$, Juan Casanova-Chafer ${ }^{2}$, Badawi Anis ${ }^{3}$, Mostafa Fedawy $^{1}$, \\ Mattia Scardamaglia ${ }^{4}$, Carla Bittencourt ${ }^{4}$, Ahmed S. G. Khalil ${ }^{5}$, Eduard Llobet $^{2}$ \\ and Xavier Vilanova*2
}

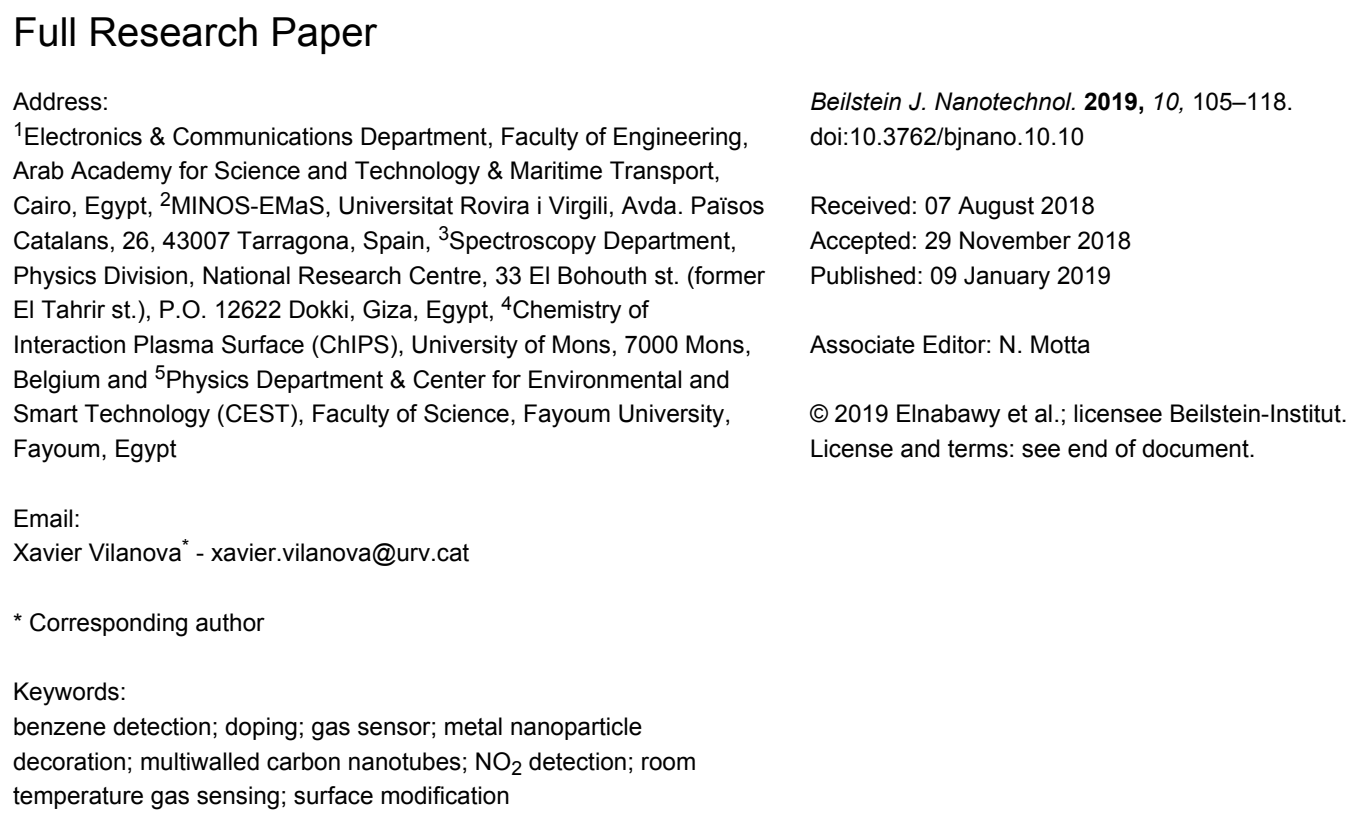

Address:

${ }^{1}$ Electronics \& Communications Department, Faculty of Engineering, Arab Academy for Science and Technology \& Maritime Transport, Cairo, Egypt, ${ }^{2}$ MINOS-EMaS, Universitat Rovira i Virgili, Avda. Països Catalans, 26, 43007 Tarragona, Spain, ${ }^{3}$ Spectroscopy Department, Physics Division, National Research Centre, 33 El Bohouth st. (former El Tahrir st.), P.O. 12622 Dokki, Giza, Egypt, ${ }^{4}$ Chemistry of Interaction Plasma Surface (ChIPS), University of Mons, 7000 Mons, Belgium and ${ }^{5}$ Physics Department \& Center for Environmental and Smart Technology (CEST), Faculty of Science, Fayoum University, Fayoum, Egypt

Email:

Xavier Vilanova* - xavier.vilanova@urv.cat

* Corresponding author

Keywords:

benzene detection; doping; gas sensor; metal nanoparticle decoration; multiwalled carbon nanotubes; $\mathrm{NO}_{2}$ detection; room temperature gas sensing; surface modification

Beilstein J. Nanotechnol. 2019, 10, 105-118. doi:10.3762/bjnano. 10.10

Received: 07 August 2018

Accepted: 29 November 2018

Published: 09 January 2019

Associate Editor: N. Motta

(C) 2019 Elnabawy et al.; licensee Beilstein-Institut. License and terms: see end of document.

\begin{abstract}
In this work, we investigated the parameters for decorating multiwalled carbon nanotubes with iron oxide nanoparticles using a new, inexpensive approach based on wet chemistry. The effect of process parameters such as the solvent used, the amount of iron salt or the calcination time on the morphology, decoration density and nanocluster size were studied. With the proposed approach, the decoration density can be adjusted by selecting the appropriate ratio of carbon nanotubes/iron salt, while nanoparticle size can be modulated by controlling the calcination period. Pristine and iron-decorated carbon nanotubes were deposited on silicon substrates to investigate their gas sensing properties. It was found that loading with iron oxide nanoparticles substantially ameliorated the response towards nitrogen dioxide.
\end{abstract}

\section{Introduction}

Carbon nanotubes (CNTs) are considered to be a very interesting material, especially after being rediscovered by Sumio Iijima in 1991 when he found multiwalled CNTs in carbon soot prepared by arc discharge [1]. During the past years, CNTs have proved to possess extraordinary electrical, mechanical, physical and chemical properties $[2,3]$. In particular, they have been ex- 
tensively researched in gas sensing applications because of their high thermal and chemical stability, high adsorption capacity and suitability for being functionalized, which enables tailoring (to some extent) their sensitivity and selectivity to the chemical environment [2-5]. CNT gas sensors often exhibit fair sensitivity to gases even when operated at room temperature. Since their electrical conductivity is affected upon the adsorption of gases, their response is often measured as a change in resistance of a CNT film. The fact that CNT gas sensors can be intrinsically low-power devices make them very attractive for their integration in ubiquitous, unattended mobile sensing nodes running on small batteries or on energy harvested from their environment [4].

Among the wide range of functionalization strategies that can be envisaged for tailoring the selectivity of CNTs towards target gases, one of the simplest consists of decorating the outer wall of CNTs with metal or metal oxide nanoparticles [6-9]. In some cases, metal or metal oxide nanoparticles show interesting catalytic properties for the decomposition of target molecules into more reactive species that, in turn, interact with CNTs. In addition, such nanoparticles shift the Fermi level of CNTs, adsorb target molecules, and help in mediating the charge transfer between adsorbates and CNTs [6,10].

Several metal oxides have been reported as useful for decorating CNTs and improving their interaction with gas molecules. Sensitivity and selectivity can be tailored by selecting the type of metal oxide employed, the size of nanoparticles and the decoration density or loading $[6,10,11]$. Metal oxides have been extensively investigated for sensing a wide range of gases [1214]. Among them, iron oxide is a semiconductor that has been used in many gas sensing applications because of its low cost and simple preparation $[14,15]$. This oxide has been used in the detection of acetone, $\mathrm{H}_{2} \mathrm{~S}$, several alcohols, $\mathrm{CO}$, acetic acid and liquefied petroleum gas (LPG) [16] and forming composites with other materials such as graphene oxide or polyaniline has been reported to detect $\mathrm{NO}_{2}[17,18]$. The decoration of CNTs with iron oxide has been reported for sensing different species in air such as acetone, $\mathrm{CO}_{2}$ and some volatile organic compounds [19-21]. Moreover, composites made of CNTs and iron oxide have been also used for sensing ammonia and $\mathrm{NO}_{x}$ $[22,23]$. Among those gases $\mathrm{NO}_{2}$ is considered one of the most dangerous air pollutants occurring both indoors, due to using of gas stoves, and outdoors from fuel powered motor vehicles and power plants especially in long-term exposure conditions. As research studies show, exposure to this gas can lead to an increase in oxidative stress in the body, resulting in behavioral and learning-memory impairments. Also, there is a consistent relationship between $\mathrm{NO}_{2}$ and respiratory and asthmatic problems at mean daily concentrations (20-80 ppb) well below air quality guidelines [24,25], which indicates the importance of fabricating such a gas sensor to be used in different applications.

In this paper, we report on a wet chemistry route that was successfully employed to chemically modify CNTs by decorating them with iron oxide nanoparticles. This inexpensive method allows control of the decoration density and nanoparticle size. The effects of changing the process parameters on the morphology of CNTs, the size of iron oxide nanoparticles and the decoration homogeneity achieved are studied and discussed in detail. The morphology, quality and chemical composition of the iron oxide decorated carbon nanotube samples were investigated employing transmission electron microscopy (TEM), Raman spectroscopy and X-ray photoelectron spectroscopy (XPS).

The differently decorated CNT samples were used to make gas sensors for detecting nitrogen dioxide. A study of the gas sensing properties of the different hybrid nanomaterials was conducted in an effort to determine the optimal functionalization parameters to maximize sensor response. The selectivity of the resulting layer for potential interfering gases such as $\mathrm{CO}$ and benzene has also been investigated as well as the effect of ambient humidity.

\section{Experimental \\ Materials}

All materials and reagents used (listed below) were of analytical grade and were used as received.

- $\mathrm{COOH}$ functionalized multiwalled carbon nanotube (MWCNTs), Nanocyl (C purity higher than 95\%)

- Nitric acid, Scharlau $\left(\mathrm{HNO}_{3} 68-70 \%\right)$

- Sulfuric acid, J. T. Baker $\left(\mathrm{H}_{2} \mathrm{SO}_{4} 95-97 \%\right)$

- Conductive silver paste, Sigma-Aldrich

- Methanol, Scharlau $\left(\mathrm{CH}_{3} \mathrm{OH} 99.9 \%\right)$

- Ethanol, Scharlau $\left(\mathrm{C}_{2} \mathrm{H}_{5} \mathrm{OH} 96 \%\right.$ extra pure and $99.5 \%$ absolute)

- Acetone, Scharlau $\left(\mathrm{C}_{3} \mathrm{H}_{6} \mathrm{O} 99.5 \%\right)$

- Dimethylformamide (DMF), Alfa Aesar $\left(\mathrm{C}_{3} \mathrm{H}_{7} \mathrm{NO}\right.$ 99.8\%)

- Iron(III) nitrate nonahydrate, Sigma-Aldrich $\left(\mathrm{Fe}\left(\mathrm{NO}_{3}\right)_{3} \cdot 9 \mathrm{H}_{2} \mathrm{O} \quad 99.95 \%\right.$ trace metal basic)

- Acetic acid, Fluka Analytical $\left(\mathrm{CH}_{3} \mathrm{COOH} 99.8 \%\right)$

\section{Decoration and characterization of carbon nanotubes}

Commercial CNTs from Nanocyl functionalized with $(\mathrm{COOH})$ groups were further chemically purified by an acidic treatment to remove any traces of catalyst or amorphous carbon. This treatment also helps in creating more active sites (e.g., some 
defects) on the side walls of the carbon nanotubes, preparing them for the decoration process. A mixture of $\mathrm{H}_{2} \mathrm{SO}_{4}$ and $\mathrm{HNO}_{3}$ was prepared at a ratio of 3:1. $200 \mathrm{mg}$ of CNTs were mixed with $12 \mathrm{~mL}$ of the acidic mixture and were stirred for one hour at room temperature. The reaction was exothermic and no cooling or water baths were used. During the reaction, ultrasonication was employed for the first 15 minutes only to assure the debundling of CNTs without damaging them. During the remaining 45 minutes, the mixture was stirred employing a magnetic stirrer $[19,26,27]$.

When the acidic treatment was completed, the resulting black slurry was filtered out from the acidic mixture using vacuum filtration and then washed with DI water for several washing cycles until the $\mathrm{pH}$ was neutralized. Then, the neutral black slurry was dried in a drying oven at $80^{\circ} \mathrm{C}$ for 4 hours.

For the decoration of carbon nanotubes, iron(III) nitrate nonahydrate was used as the iron precursor. $50 \mathrm{mg}$ of the acidic-activated carbon nanotubes were added to $50 \mathrm{~mL}$ of solvent together with a corresponding amount of $\mathrm{Fe}\left(\mathrm{NO}_{3}\right)_{3} \cdot 9 \mathrm{H}_{2} \mathrm{O}$ salt. Different solvents, methanol, ethanol, acetone and DMF, as well as different amounts of salt (with ratios 1:1, 1:1.3 and 1:1.5 for $\mathrm{CNT} / \mathrm{Fe}$ weights) were tested to check the effect of both parameters in the effectiveness of the decoration. The mixtures were stirred using a magnetic stirrer for 60 minutes. In a first attempt, the mixtures were heated to $80^{\circ} \mathrm{C}$ to completely evaporate the solvent. This approach did not succeed, as commented in the results and discussion section, so a new approach was designed. In this second attempt, the mixtures were heated to $80^{\circ} \mathrm{C}$ until $40 \mathrm{~mL}$ of the solvent was evaporated. The remaining solution was then ultrasonicated for 15 minutes then heated at $80{ }^{\circ} \mathrm{C}$ on a hotplate with a magnetic stirrer till the complete evaporation of the solvent. Once dried, the resulting powder was exposed to vapors of acetic acid for 15 minutes and later heated for 20 minutes at $80{ }^{\circ} \mathrm{C}$ to remove all the physically absorbed acetic acid [28]. Finally, the powder was calcined at $450{ }^{\circ} \mathrm{C}$ during either 15 or 30 minutes. In this way the effect of the calcination time on the decoration process was also evaluated.

The chemical composition of the decorated CNTs were measured by X-ray photoelectron spectroscopy (XPS) using a Versaprobe PHI 5000 from Physical Electronics, equipped with a monochromatic $\mathrm{Al} \mathrm{K} \alpha \mathrm{X}$-ray source at a base pressure of about $10^{-9}$ mbar. The sample powders were mounted on double-sided conductive vacuum tape. The X-ray photoelectron spectra were collected at a take-off angle of $45^{\circ}$ with respect to the electron energy analyzer and the spot size was $200 \mu \mathrm{m}$. A pass energy (PE) of $20 \mathrm{eV}$ was used for the high-resolution spectra (Fe 2p, C 1s and O 1s), while $\mathrm{PE}=100 \mathrm{eV}$ was used for the survey spectrum, accounting for an overall energy resolution of about $0.5 \mathrm{eV}$. Different points on each sample were measured in order to ensure the homogeneity. The chemical composition was then evaluated by using CASA XPS software.

TEM images were collected using a JEOL 1011 transmission electron microscope operating at $100 \mathrm{kV}$. The samples were dispersed in ethanol and a drop of resultant suspension was poured on carbon-coated copper grids.

The Raman spectra for the different samples was characterized using a Renishaw inVia spectrometer as the powder samples were mounted on clean glass slides. The samples were excited with a green $(514 \mathrm{~nm})$ laser using $50 \%$ laser power and the exposure time was $10 \mathrm{~s}$.

X-ray diffraction (XRD) patterns were recorded at room temperature using a 202964 Panalytical Empryan diffractometer (Central Laboratory, Beni Suef University, Egypt) with a $\mathrm{Cu} \mathrm{K} \alpha$ monochromatic radiation $(k=1.54056)$ operating at $40 \mathrm{kV}$ and $30 \mathrm{~mA}$ from $5.0200^{\circ}$ to $79.9800^{\circ}$ with a $2 \theta$ step size of 0.0400 and a scan step time of $0.50 \mathrm{~s}$ in a continuous scanning mode.

\section{Fabrication and testing of gas sensors}

In order to check the effect of the different decorations on the gas sensing properties of modified CNTs, simple sensing devices were fabricated. For that purpose, small rectangular pieces of a silicon wafer, previously oxidized at $1100{ }^{\circ} \mathrm{C}$ for 6 hours, were used as substrate. Heaters were attached to the back side of the sensor substrate using silver paste from SigmaAldrich. The substrates were heated in the oven at $120{ }^{\circ} \mathrm{C}$ for 30 minutes to cure the silver paste.

A dispersion in DMF was prepared with a concentration of $0.1 \mathrm{mg} / \mathrm{mL}$ of the modified CNT samples to be deposited. Then, the solution was ultrasonicated for 15 minutes before being deposited onto the silicon substrates. Two different approaches were used for depositing iron-loaded CNT films on the substrates: drop coating and air brushing. In drop coating, the substrate was heated on a hot plate up to $160{ }^{\circ} \mathrm{C}$ while the dispersion of CNTs in DMF was dropped by means of a pipette (drop by drop). The DMF was instantaneously evaporated when the drop was in contact with the heated silicon substrate, leaving the iron-loaded CNTs physically attached to it. In air brushing, the substrate was also heated to $160{ }^{\circ} \mathrm{C}$ while the suspension of CNTs in DMF was airbrushed onto the top of the substrate. As in the previous case, the solvent was instantaneously evaporated when in contact with the heated substrate, leaving the ironloaded CNTs physically attached to it. To delimitate the area where the CNTs were deposited, a shadow mask of adhesive Kapton was used. This second approach leads to thinner active 
layers. The differences in the results for both approaches can be seen in the Supporting Information File 1 (Figure S1).

After the previous steps, heaters and the CNT layer were connected to a printed circuit board (PCB) using platinum wires. Those wires were attached to the heaters and CNT layers using silver paste that was cured in an oven at $120{ }^{\circ} \mathrm{C}$ for 30 minutes. To connect the Pt wires to the $\mathrm{PCB}$ we used tin wire and a soldering iron.

Wire bonded sensors ready for testing can be seen in the Supporting Information File 2 (Figure S2). The silicon substrates onto which carbon nanotubes were deposited were glued to an alumina substrate that included a platinum heater employing a thermally conductive epoxy.

A teflon chamber, which allowed allocating up to four sensors, was used for testing the gas sensing properties of the different nanomaterials. This chamber is shown in Supporting Information File 3 (Figure S3). A gas cylinder with a 100 ppm $\mathrm{NO}_{2}$ concentration balanced in dry air was used jointly with a set of mass flow controllers to generate the desired concentrations. The gas flux was fixed to $100 \mathrm{sccm}$ during the whole experiments. The sensor response is defined as

$$
\left(R_{\mathrm{G}}-R_{0}\right) / R_{0}
$$

where $R_{\mathrm{G}}$ is the sensor resistance when exposed to $\mathrm{NO}_{2}$ and $R_{0}$ is the sensor response when exposed to air.

Before starting any experiment, the sensors were heated while dry synthetic air was flowed in order to clean the sensor surface.
Afterwards, different concentrations of $\mathrm{NO}_{2}$ gas (5 ppm, $10 \mathrm{ppm}, 20 \mathrm{ppm}, 50 \mathrm{ppm}$ and $100 \mathrm{ppm}$ ) were successively pumped into the test chamber with the sensors operated at room temperature. The cycles consisted of 30 minutes of exposure to $\mathrm{NO}_{2}$ diluted in air and 3 hours of recovery in dry air.

To determine the selectivity of the sensor for carbon monoxide (CO) and benzene $\left(\mathrm{C}_{6} \mathrm{H}_{6}\right)$, gas cylinders with a $100 \mathrm{ppm} \mathrm{CO}$ and 10 ppm $\mathrm{C}_{6} \mathrm{H}_{6}$ concentrations respectively, balanced in dry air, were used with the previously described set-up. To create the desired humidity in order to check the effect of moisture on the sensor response, a controlled amount of water was mixed with the gas flow by means a liquid mass flow controller.

\section{Results and Discussion Acidic purification and decoration of carbon nanotubes}

Figure 1 shows TEM images for the CNTs before and after the acidic treatment and, as shown, no significant changes are visible in the carbon nanotubes.

Since using the first approach for the decoration of CNTs led to the formation of large agglomerates of iron-loaded carbon nanotubes that could not be dispersed even after a sonication process in ethanol for 30 minutes (as can be seen in Figure S4, in Supporting Information File 4), this first approach was discarded and we focused our efforts in the second approach.

Accordingly, the next step was to determine the best solvent for obtaining a well dispersed powder with homogeneous nanoparticle coverage. To analyze the effect of the solvent on the nanoparticle distribution, solutions with the four solvents considered (ethanol, methanol, acetone and DMF) were prepared using a

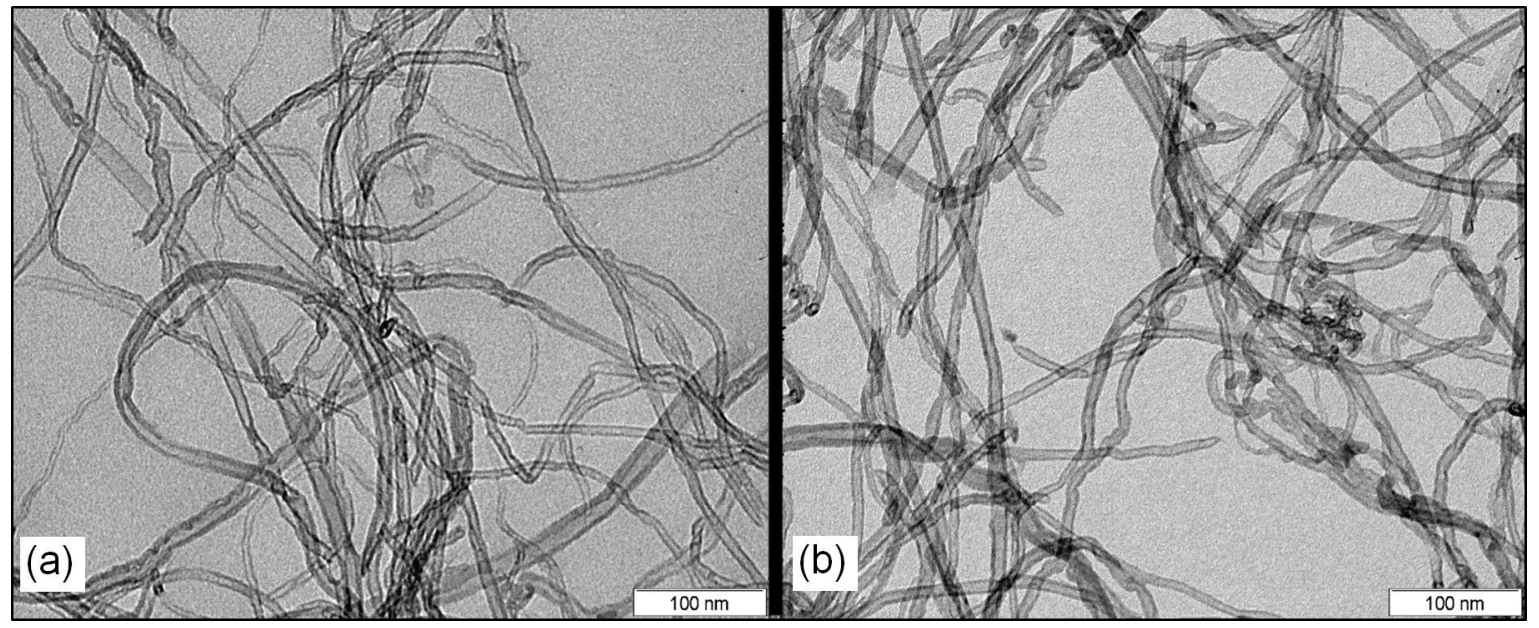

Figure 1: TEM images for $\mathrm{COOH}-\mathrm{CNTS}$ (a) before acidic treatment and (b) after acidic treatment. 
1:1.5 proportion in weight between carbon nanotubes and iron(III) nitrate nonahydrate and calcined for 30 minutes. TEM images of the results are summarized in Figure 2. As can be seen, both ethanol and methanol led to a homogenous distribution of the nanoparticles onto the carbon nanotubes. Moreover, the size of the nanoparticles in those cases was also homogeneous. Nevertheless, the decoration homogeneity was slightly better for methanol than for ethanol. On the other hand, acetone and DMF had a negative effect on both the decoration distribution and particle size. As we can see in the case of acetone, the dispersion of the nanoclusters is not uniform or homogenous and some areas have high decoration density while some other areas have very low decoration density. Also, in the case of DMF we can notice that dispersion of the nanoclusters was better than for acetone, but still some areas have a high density of decoration in which agglomerates of large particle size are formed.

According to these results, methanol was chosen as the most suitable solvent to be used in the production of iron-loaded CNT samples for further analysis, including the production of gas sensors.
Once the best solvent was identified, it was necessary to determine the effect of the amount of iron oxide precursor employed on the decoration results (i.e., density and homogeneity of the loading, particle size). TEM images for different samples with different $\mathrm{CNT}$ /iron salt ratios were taken to investigate their effect on the decoration density, as shown in Figure 3. We can see that decoration density of $\mathrm{CNT} / \mathrm{Fe}$ oxide increases by increasing the amount of iron salt, while the particle size was not affected.

Statistical analysis for the three samples shows that the average particle size of the NP does not increase when increasing the decoration dose. The mean particle size was found to be 3.44 , 3.46 and $3.31 \mathrm{~nm}$ for decoration ratios of $1: 1,1: 1.3$ and 1:1.5, respectively (size distribution histograms can be found in Supporting Information File 5, Figure S6).

For all the decorated samples we have used the same source of acidic-functionalized MWCNTs. Accordingly, all the MWCNTs used have, more or less, the same defect size and distribution on the side walls. As the amount of iron salt increases, more iron precursor will be able to reach and interact

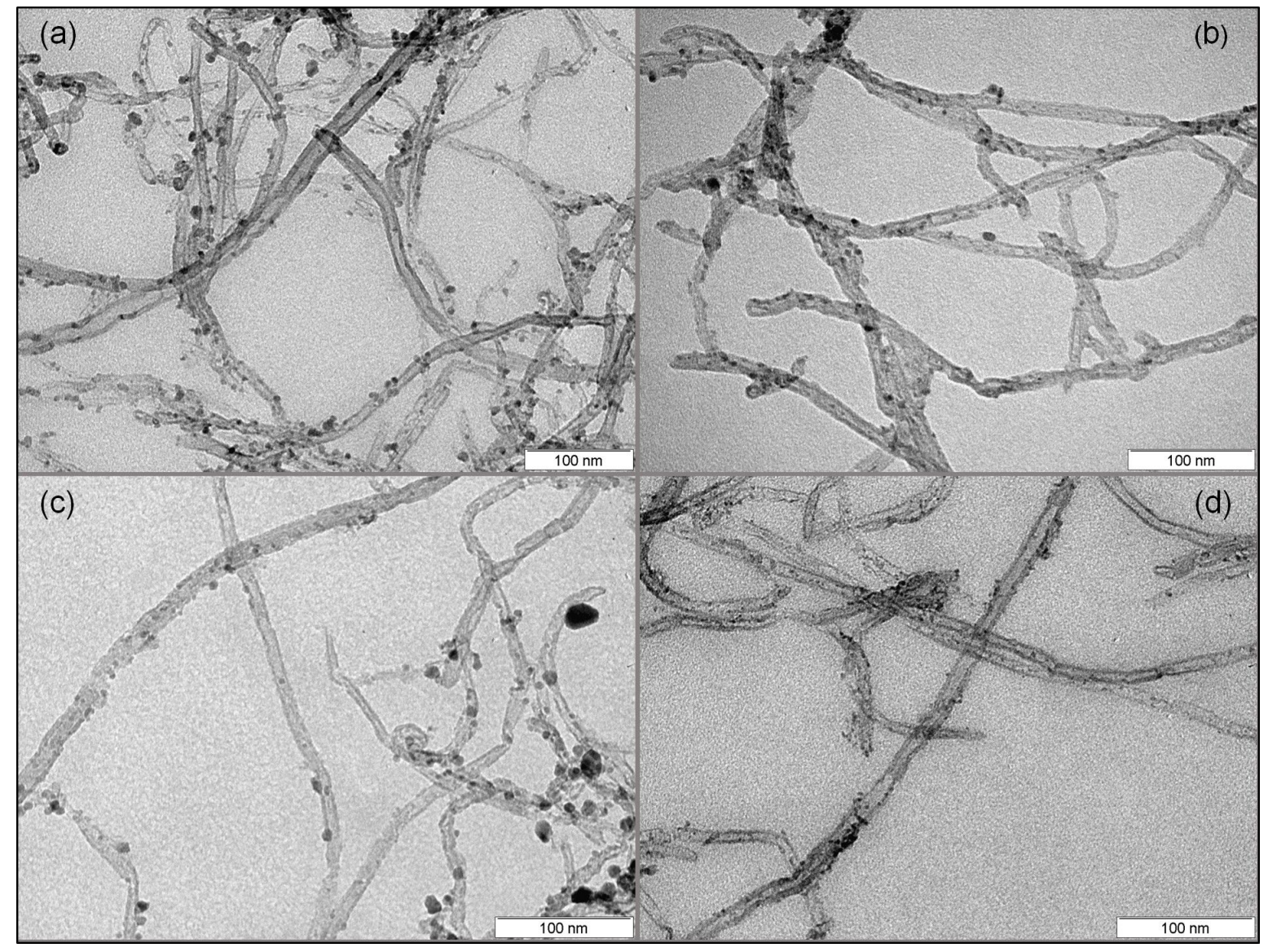

Figure 2: Different decoration homogeneity using different solvents, methanol (a), ethanol (b), DMF (c) and acetone (d). 


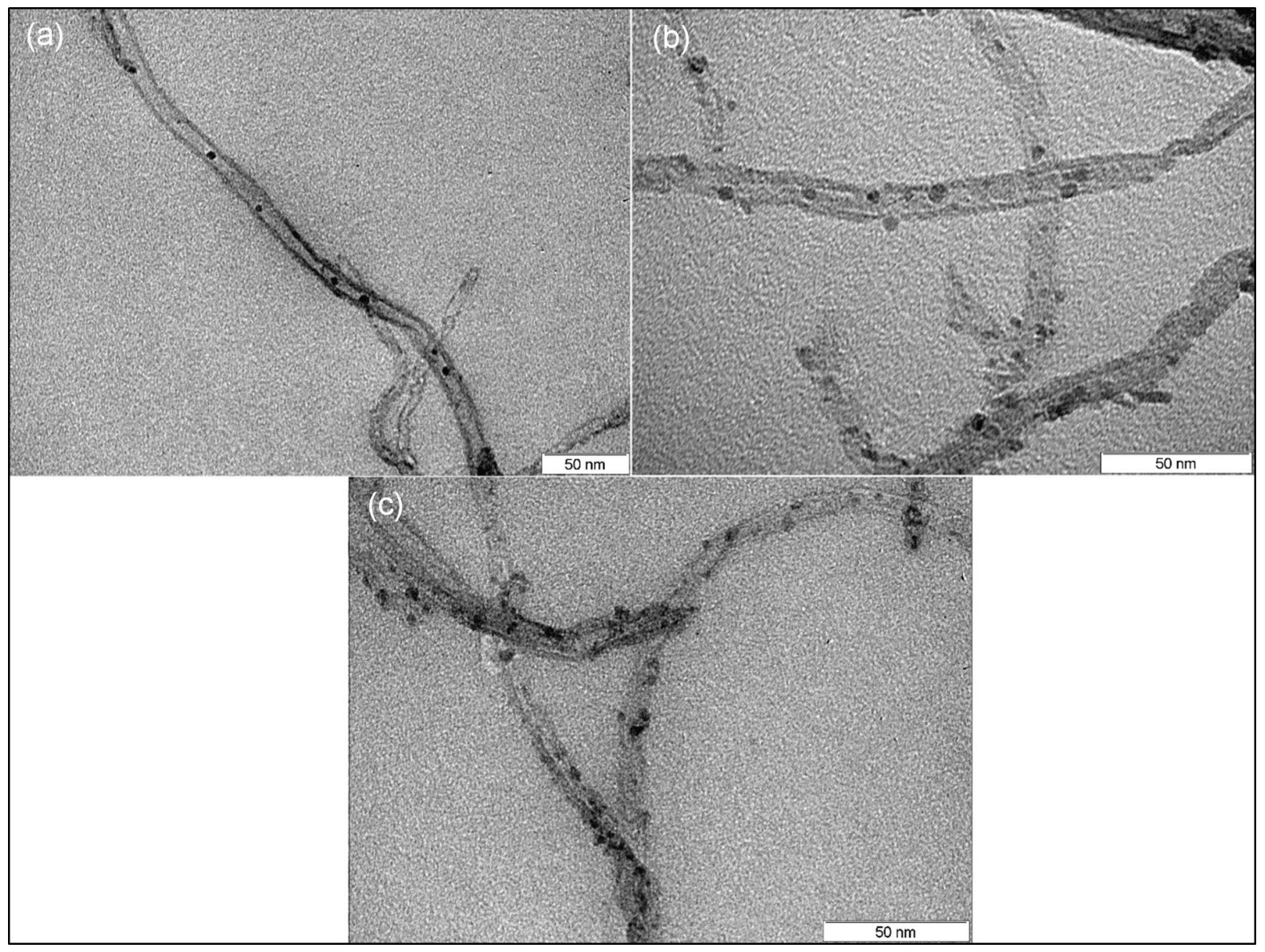

Figure 3: Different decoration densities for different decoration ratios of 1:1 (a), 1:1.3 (b) and 1:1.5 (c).

with a larger number of defects on the MWCNTs side walls. Therefore, the density of the formed iron nanoparticles will increase. However, the average particle size of those nanoparticles will be the same because the side defects have the same size distribution for all samples.

In addition, HRTEM imaging for the anchored iron oxide nanoparticles on the MWCNTs surface was performed and the selected area electron diffraction (SAED) pattern for was identified, as shown in Figure 4. The image shows the high crystallinity of the prepared iron oxide nanoparticles and the selected area electron diffraction (SAED) pattern of the iron oxide nanoparticles (see inset of Figure 4) clearly shows the diffraction rings of a typical cubic structure.

XPS was performed to investigate the chemical composition of the samples and, in particular, to determine the oxidation state of iron in the nanoparticles that decorate the CNT sidewalls. These results are shown in Figure 5. A description and coding of the samples analyzed as well as their chemical composition derived from the XPS analysis is summarized in Table 1. The

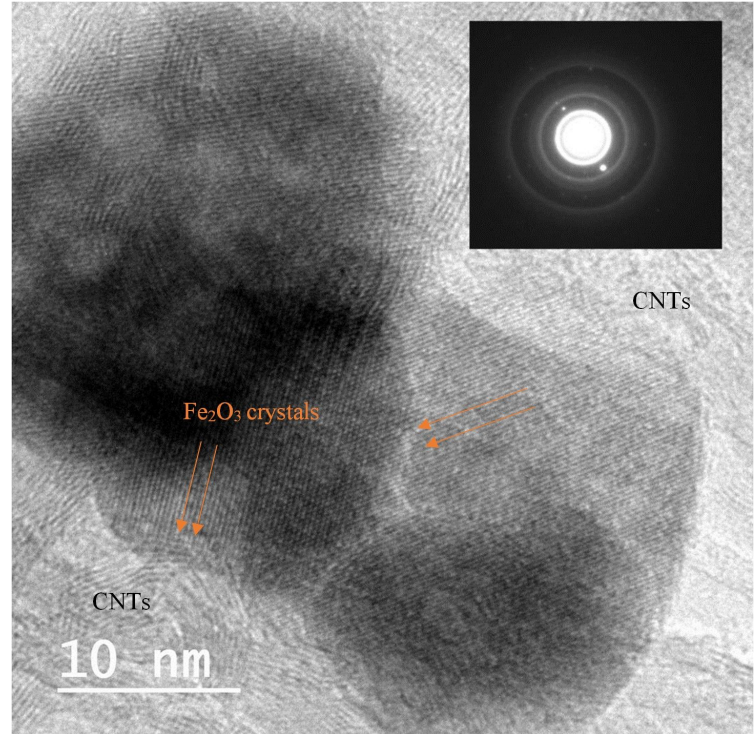

Figure 4: High magnification HRTEM images of MWCNTs decorated with $\mathrm{Fe}_{2} \mathrm{O}_{3}$ nanoparticles. The inset shows the electron diffraction pattern (SAED) for the selected area. 

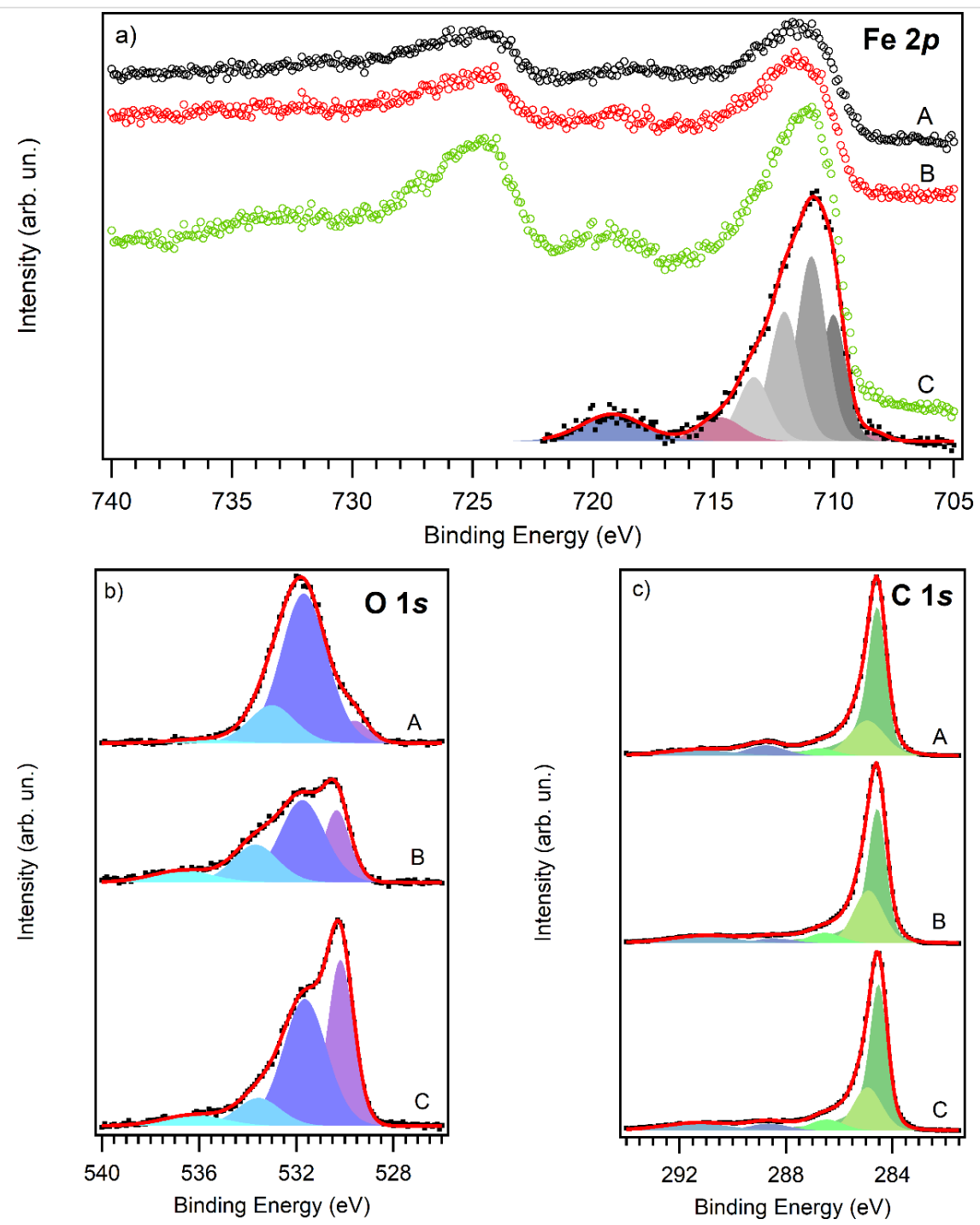

Figure 5: XPS core level spectra of Fe 2p with a fitting curve for sample C (a), O 1s (b) and C 1s (c) for the samples A (black curve), B (red curve) and $C$ (green curve). The $C 1$ s spectra has been normalized and aligned.

\begin{tabular}{|c|c|c|c|c|}
\hline Sample & Description & $\mathrm{C}(\%)$ & $\mathrm{O}(\%)$ & $\mathrm{Fe}(\%)$ \\
\hline A & 2nd decorating approach with a ratio of (1 CNT/1 Fe salt); not calcined & 78.0 & 17.0 & 2.9 \\
\hline B & 2nd decorating approach with a ratio of (1 CNT/1 Fe salt); calcined for 30 minutes & 86.0 & 11.0 & 2.5 \\
\hline $\mathrm{C}$ & 2nd decorating approach with a ratio of (1 CNT/1.5 Fe salt); calcined for 30 minutes & 75.0 & 19.0 & 5.7 \\
\hline
\end{tabular}

values of the content for each element have been evaluated at different points on the sample and averaged, with an error as low as $\pm 0.5 \%$. The concentration of iron well reflects the decorating ratio, with sample $\mathrm{C}(1 \mathrm{CNT} / 1.5 \mathrm{Fe}$ Salt) being the one with the highest $\mathrm{Fe}$ content. Residual nitrogen and sodium can be found in samples A and C respectively, which is probably due to some contamination during the fabrication process that we assume will not affect sensor performance.
Figure 5a shows the typical Fe 2p XPS spectrum recorded on the studied samples. The spectrum is composed of two main structures centered at 712 and $725 \mathrm{eV}$ corresponding to photoelectrons emitted from $\mathrm{Fe} 2 \mathrm{p}_{3 / 2}$ and $\mathrm{Fe} 2 \mathrm{p}_{1 / 2}$, respectively. Two satellite structures are also present centered at 719 and $733 \mathrm{eV}$. As can be seen in the figure, the $\mathrm{Fe} 2 \mathrm{p}_{3 / 2}$ region for sample $\mathrm{C}$ can be reproduced using a decomposition of four peaks (grey components), plus a surface peak (purple component) and a 
shake-up satellite (blue component) according to Grosvenor et al. [29]. The energy position of these peaks, in particular the first one of the 4-component multiplet $(710.0 \mathrm{eV})$ and the satellite $(719.2 \mathrm{eV})$, indicates the presence of iron in the Fe(III) oxidation state $\left(\mathrm{Fe}^{3+}\right)$, characteristic of $\mathrm{Fe}_{2} \mathrm{O}_{3}$ and oxide-hydroxide. It is reported that the typical value for the satellite peak of $\mathrm{Fe}^{2+}(\mathrm{FeO})$ is $715.5 \mathrm{eV}$ [30] and main 2p peak centered at $708 \mathrm{eV}$ [31], while metallic iron has the main peak at much lower binding energy $(706.7 \mathrm{eV})$.

The $\mathrm{O}$ 1s core level spectra, shown in Figure 5b, was reproduced using four peaks. The first one at $530.2 \mathrm{eV}$ is attributed to oxygen in iron oxide: its contribution is higher in the spectra recorded on sample $\mathrm{C}$, where the relative amount of iron was found to be the highest. The peak at $531.7 \mathrm{eV}$ is mostly due to hydroxyl $\mathrm{OH}$ and $\mathrm{O}-\mathrm{C}$ groups, while the remaining two peaks are attributed to other $\mathrm{O}-\mathrm{C}$ groups and adsorbed water [32,33].

$\mathrm{C}-\mathrm{O}$ contributions can be also observed in the $\mathrm{C} 1 \mathrm{~s}$ core level spectra in Figure $5 \mathrm{c}$ by the presence of the peak at $288.6 \mathrm{eV}$. This contribution is higher in the spectrum recorded on sample A, where the highest amount of oxygen was found. The line shape of the C1s spectra recorded is typical for carbon nanotubes, with an asymmetric and narrow $\mathrm{sp}^{2}$ peak at $284.5 \mathrm{eV}$; this is followed by a second contribution due to carbon in amorphous or $\mathrm{sp}^{3}$ configuration at $285.0 \mathrm{eV}$ [34]. The presence of these peaks associated with $\mathrm{C}-\mathrm{O}$ bonds indicates that the functionalization of the CNTs (with $\mathrm{COOH}$ ) is still present after the decoration process.

The fact that the nanoparticles consisted of $\mathrm{Fe}_{2} \mathrm{O}_{3}$ was further confirmed by XRD characterization. For this purpose, pure iron oxide nanoparticles were prepared following the procedure described above. Figure 6 shows the spectra of the iron oxide nanoparticles and iron oxide nanoparticle-decorated nanotubes. These last results correspond to the sample with a 1:1 decoration ratio and calcined for $30 \mathrm{~min}$. As it can be seen, the pattern of the $\mathrm{Fe}_{2} \mathrm{O}_{3}$ nanoparticles corresponds to a cubic crystalline structure, which confirms the HRTEM results. In the XRD pattern for $\mathrm{Fe}_{2} \mathrm{O}_{3} / \mathrm{CNTs}$ the characteristic peak at $25.994^{\circ}$ attributed to plane (002) of the CNTs can be clearly identified. The other diffraction peaks at $35.6^{\circ}, 43.15^{\circ}, 53.28^{\circ}, 57.3^{\circ}, 63.12^{\circ}$ can be attributed to planes (311), (400), (422), (511) and (440) of the cubic $\mathrm{Fe}_{2} \mathrm{O}_{3}$ phase.

\section{Gas sensing properties}

Samples B and C were used to prepare sensors using the dropcoating approach to check the effect of decoration ratio on the response. An additional sensor was prepared using pristine carbon nanotubes with the airbrushing approach. Figure 7 shows electrical resistance against time.

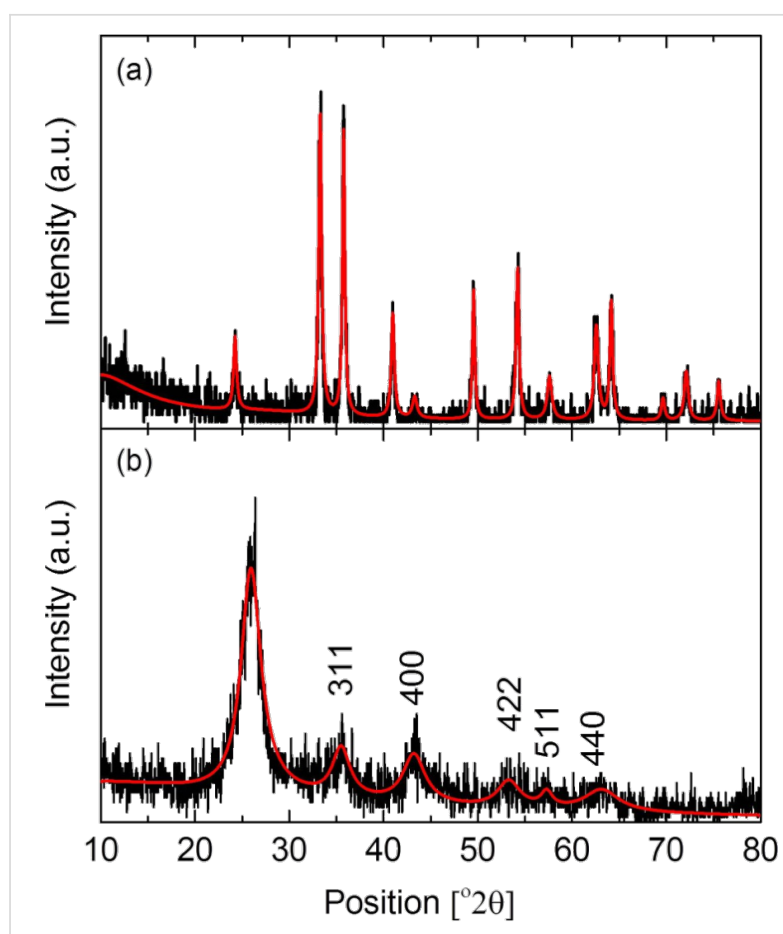

Figure 6: $\mathrm{XRD}$ pattern for $\mathrm{Fe}_{2} \mathrm{O}_{3}$ nanoparticles (a) and decorated CNTs with $\mathrm{Fe}_{2} \mathrm{O}_{3}$ nanoparticles (b).

Nitrogen dioxide was found to strongly interact with carbon nanotube sensors, and as a result, the sensors did not fully recover their baseline resistance value during the cleaning phase, which was conducted at room temperature without heating. Applying mild heating or UV light have been reported useful for fully recovering the baseline after exposure to nitrogen dioxide [10]. Therefore, for calculating the response to any given nitrogen dioxide concentration, the value of $R_{0}$ was taken as the value of the sensor resistance before being exposed to the corresponding gas concentration and the value of $R_{\mathrm{G}}$ was fixed as the value of resistance at a fixed time after an $\mathrm{NO}_{2}$ exposure of 10 minutes.

Figure 8 shows the calibration curves for different concentrations of $\mathrm{NO}_{2}$. Response (\%) is defined as $100 \times\left(R_{\mathrm{G}}-R_{0}\right) / R_{0}$. As derived from Figure 8, Sample B with a 1:1 decoration ratio shows better response than sample $\mathrm{C}$ and obviously better than pristine CNTs.

These results allow us to conclude that the decoration with iron oxide improves sensor performance in the detection of $\mathrm{NO}_{2}$. Regarding the amount of iron oxide introduced, the best result is obtained for the lower decoration ratio of $1: 1$ which is considered to be the optimum decoration ratio.

By comparing these results to other results in the literature, we can conclude that there is an optimum decoration ratio which 

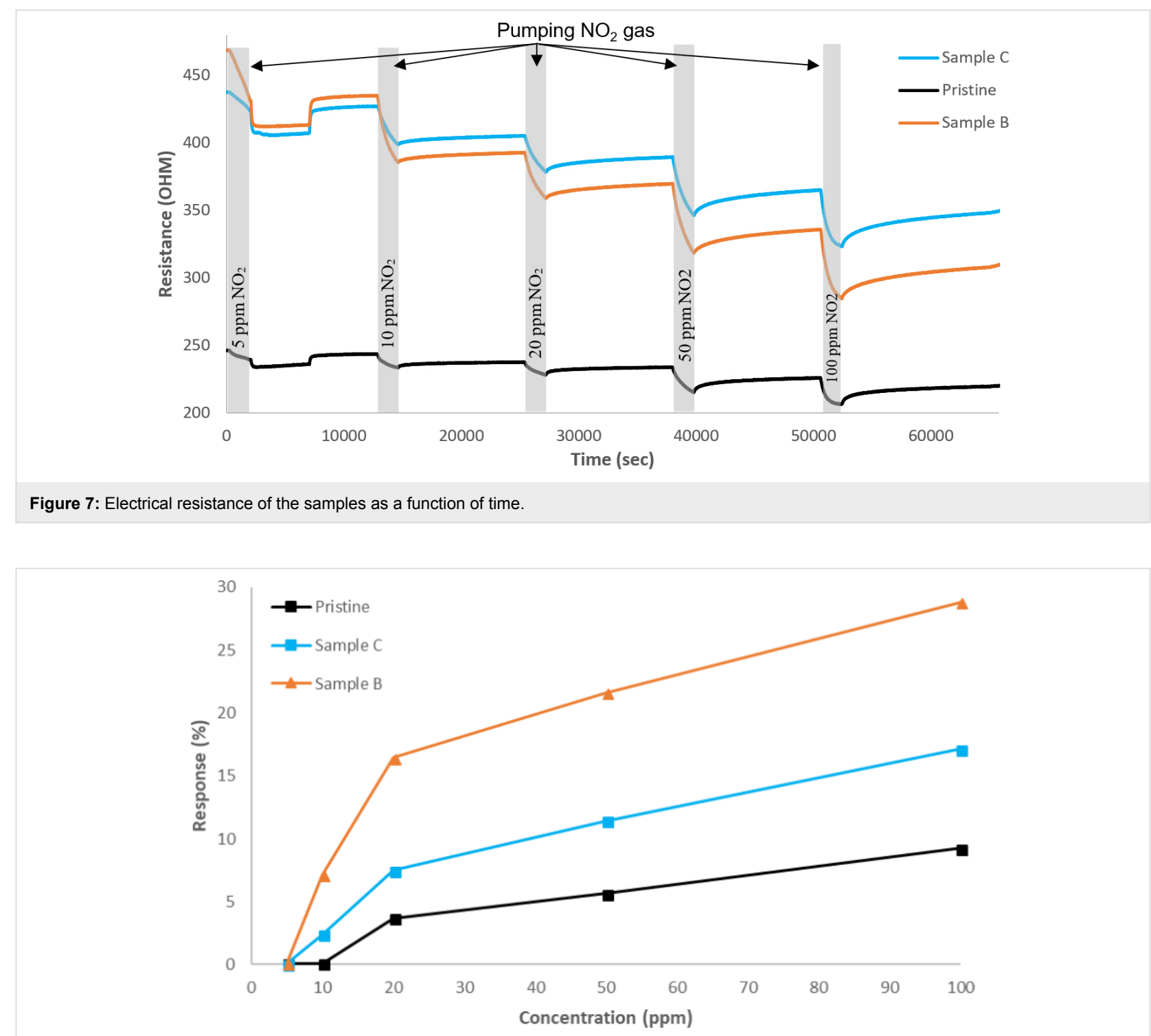

Figure 8: Effect of decoration ratio on the gas sensing performance.

gives us the highest response, as the response increases with increasing decoration ratio dose until an optimum decoration density is reached and afterwards the response decreases [6,19,28]. In fact, the obtained results are better regarding the intensity of the sensor response, as compared to those obtained by Chuanfei Hua et al. [23] using a composite of SWCNT- $\mathrm{Fe}_{2} \mathrm{O}_{3}$, although their sensors show faster response time.

\section{Studying effect of calcination period on nanocluster size}

TEM images for two samples with the same decoration ratio $(\mathrm{CNT} / \mathrm{Fe}=1: 1.5)$ but with different calcination periods of 15 or 30 minutes were taken to investigate the effect of the duration of the calcination on the size of iron nanoclusters. This is shown in Figure 9a. In addition, the nanocluster size distribution can be found in Supporting Information File 5, Figure S5. It can be concluded that the nanocluster size increases with increasing calcination time.

Also, the Raman spectra for pristine CNTs along with decorated samples of $\mathrm{CNT} / \mathrm{Fe}=1: 1.5$, which were calcined for 15 or 30 minutes, were studied to determine the effects of the calcination period on the quality of CNTs in comparison to noncalcined decorated CNTs. These results are shown in Figure 9b.

By analyzing the Raman spectra, we conclude that by increasing the calcination time, the quality of the CNTs slightly decreases. We also notice that the change in $I_{\mathrm{D}} / I_{\mathrm{G}}$ between pristine and decorated CNTs is not very high. This is expected because the commercial CNTs provided from Nanocyl are of 

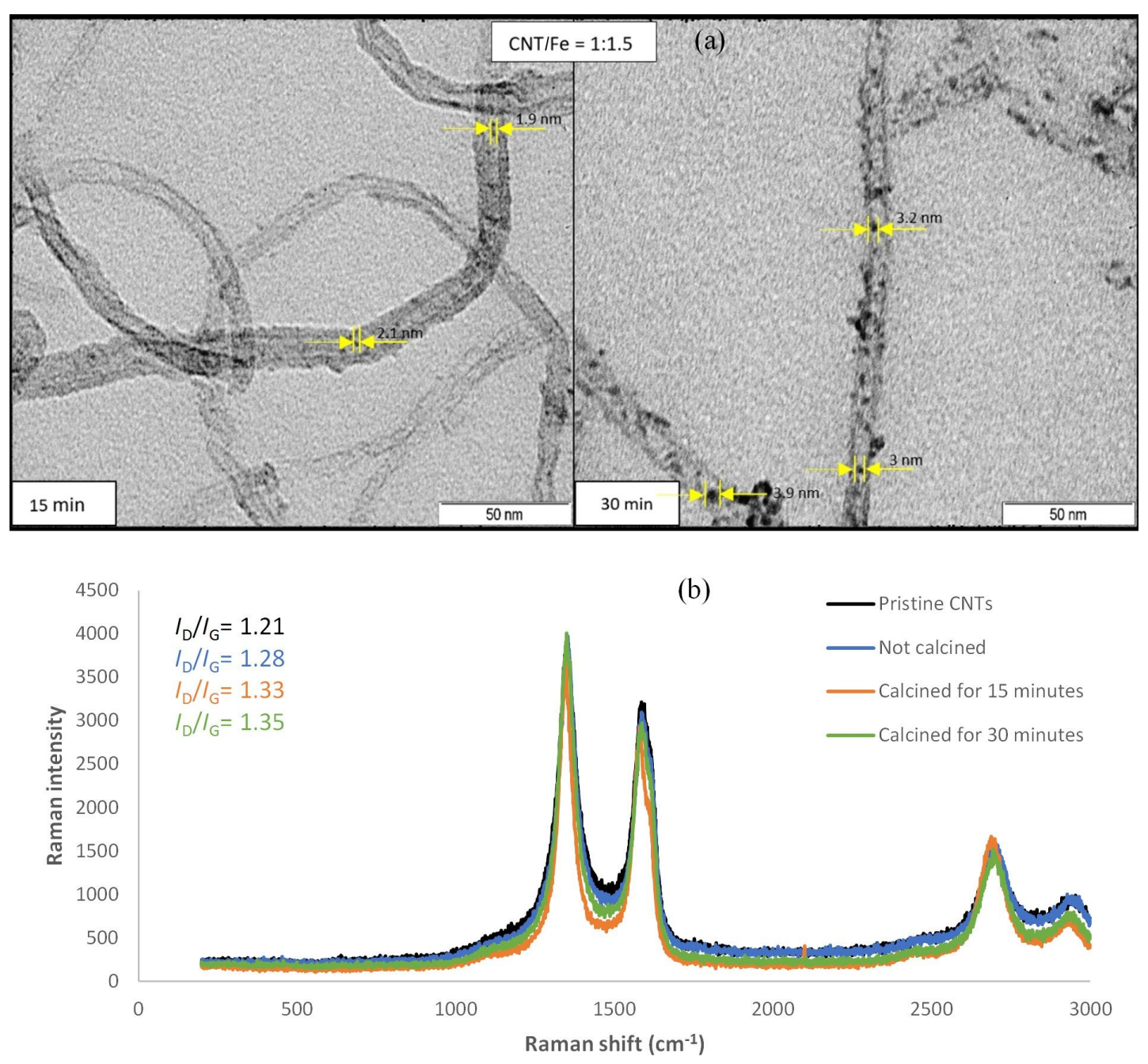

Figure 9: TEM images showing nanocluster size (a) after calcination for 15 minutes and 30 minutes for a 1:1.5 decoration ratio and Raman spectra for pristine CNTs and decorated CNTs with different calcination periods for (1:1.5) decorated COOH-CNTs (b).

low purity $(95 \%)$ in analytical terms. In addition, the CNTs were already functionalized, so it is logical that a relatively high $\mathrm{D} / \mathrm{G}$ ratio is obtained before performing any treatment or decoration. This low crystallinity means that a high concentration of disordered $\mathrm{sp}^{2}$ carbon in relation to the presence of stretching $\mathrm{C}-\mathrm{C}$ bonds is already present in as-purchased $\mathrm{CNT}$ samples. This makes it difficult to significantly increase defects in CNTs after performing further treatment and decoration.

In order to check the influence of nanoparticle size on the sensing capabilities of the CNTs, carbon nanotubes corresponding to sample A calcined for 15 or 30 minutes were used to implement sensors by the drop-coating approach. The previous sensor based on pristine CNTs was also used for comparison. Two different concentrations of $\mathrm{NO}_{2}$ gas ( $5 \mathrm{ppm}, 10 \mathrm{ppm}$ ) were pumped into the test chamber in this case. The results are shown in Figure 10.
As shown in Figure 10, the response of the sensor that employed carbon nanotubes calcined for 30 minutes, i.e., the one with larger iron oxide particles, is higher than the sensor based on iron oxide decorated CNTs calcined for 15 minutes.

These results confirm again that the decoration with iron oxide enhances the sensor response to $\mathrm{NO}_{2}$, obtaining better results for carbon nanotubes decorated with iron oxide nanoparticles of larger size. This is consistent with the literature, in which heat treatment on sensors doped with an optimum doping ratio can cause both an increase in the size of decorating nanoparticles and an enhancement in the response of the sensor [6].

In order to check if the deposition method (drop-coating thick film or airbrushing thin film) has an influence on the sensor behavior, an additional sensor using CNTs corresponding to sample B was prepared by air brushing. Differences in morpholo- 


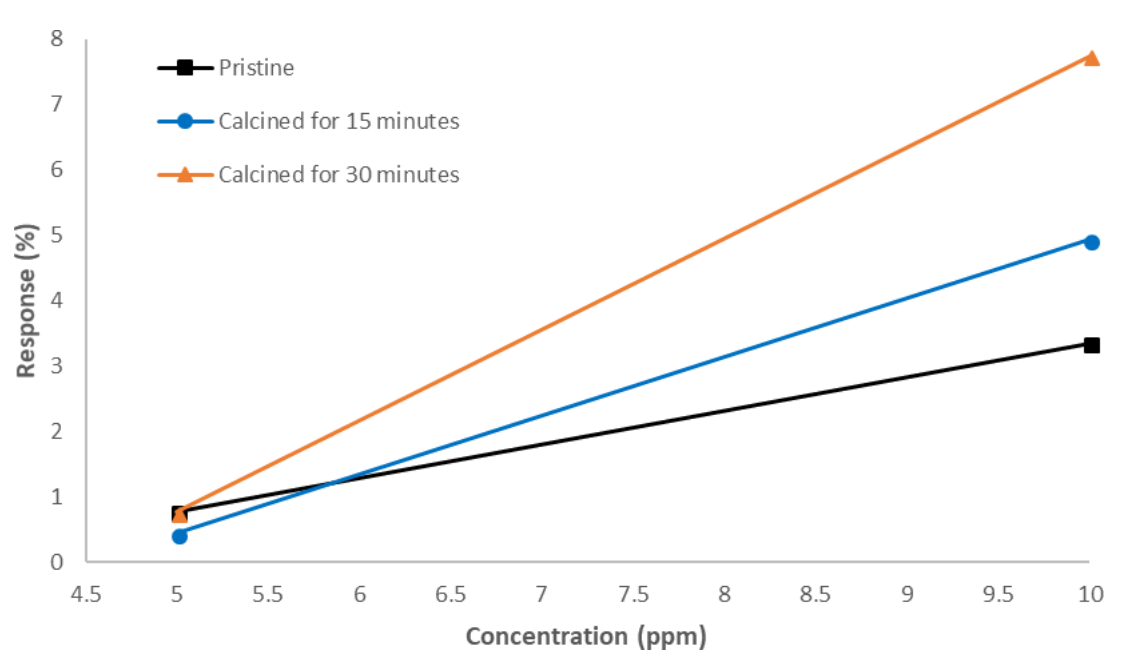

Figure 10: Effect of calcination period on the gas sensing performance.

gies between the two approaches followed for the deposition procedure (drop coating and air brushing) can be found in Supporting Information File 1, Figure S1.

This new sensor, together with the one based on pristine nanotubes fabricated using the same approach, and the sensor based on CNTs of sample B, but obtained by drop coating were tested.

The results are shown in Figure 11. As it can be seen, the thin layer sensor obtained by airbrushing decorated nanotubes showed better response than the thick film sensor obtained by drop coating. Once more, the results confirm that the decoration of the nanotubes using iron oxide is a good approach to enhance the sensor response to $\mathrm{NO}_{2}$. In this case, we are comparing sensors implemented employing the same procedure, using both decorated and pristine nanotubes. Moreover, the airbrushed sensor showed the best response.

In order to check the selectivity of the best performing sensor, measurements for $10 \mathrm{ppm}$ of benzene and $100 \mathrm{ppm}$ of CO were performed. Although the concentrations of both gases were quite high, the sensor showed no response to carbon monoxide while the response to benzene was lower than $0.06 \%$, confirming a good selectivity for the target gas (i.e., nitrogen dioxide).

Finally, to check the effect of humidity in the performance of the sensor, a new set of measurements for $\mathrm{NO}_{2}$ were performed. In this case, the relative humidity was set to $50 \%$. Comparing these results with the ones performed with dry air (relative

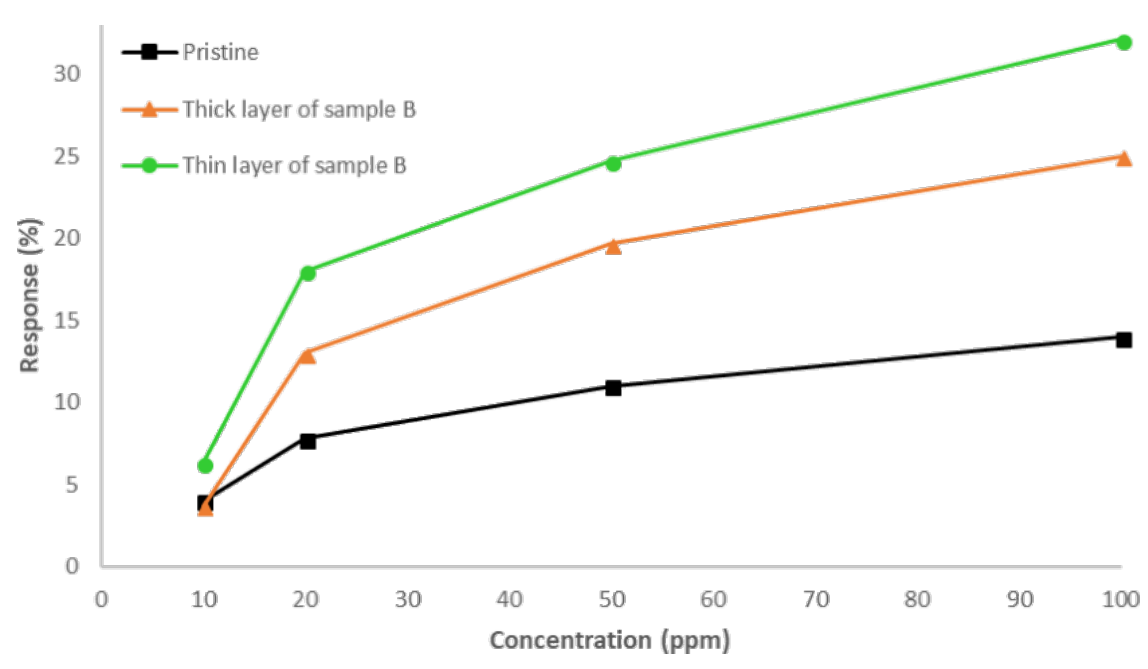

Figure 11: Effect of layer homogeneity and thickness on the gas sensing performance. 
humidity was around $3 \%$ ), one can realize that the sensor, when working in a more humid environment, shows faster response. That is, the presence of water vapor improves the performance of the sensor. The results of these measurements are shown in Figure 12. This enhancement in nitrogen dioxide response under humid conditions can be attributed to the water mediated adsorption of $\mathrm{NO}_{2}$ on iron oxide nanoparticles, as previously reported for semiconductor metal oxide chemoresistors [35].

A deeper analysis of the sensor behavior reflected in Figure 7 and Figure 11 shows that both pristine and decorated CNT films behave as a p-type semiconductor. When nitrogen dioxide reacts with the active layer, the molecule traps electrons from the active layer, increasing its conductivity, because this increases the concentration of holes, which act as main charge carriers.

Comparing the behavior of pristine and decorated CNTs, one can clearly see that the decoration process leads to an increase in the electrical resistance of the active layer. This fact can be attributed to the $\mathrm{p}-\mathrm{n}$ junctions formed between the p-type CNTs and the n-type iron oxide nanoparticles, with the formation of associated depletion layers. The p-type behavior of the decorated nanotubes suggests that, when the sensor is exposed to $\mathrm{NO}_{2}$, the response is mainly due to the CNTs. In this case, the iron oxide NPs contribute to the enhancement of the response via a reduction of their associated depletion layer when $\mathrm{NO}_{2}$ molecules adsorb on the surface of NPs, which increases the conductivity of the layer. Nevertheless, there is another possible explanation. It has been reported that $\mathrm{Fe}_{2} \mathrm{O}_{3}$ can turn from n-type to p-type, especially in oxidizing ambient environments [36]. This possible change in the semiconducting behavior of $\mathrm{Fe}_{2} \mathrm{O}_{3}$ could be the reason why the response to other reducing gases such as benzene or $\mathrm{CO}$ has been found to be very low.
Nevertheless, a deeper study is necessary to better determine the mechanisms responsible for sensor response.

\section{Conclusion}

The decoration of MWCNTs with $\mathrm{Fe}_{2} \mathrm{O}_{3}$ using an inexpensive method based on wet chemistry has shown to be a good approach for enhancing the detection of $\mathrm{NO}_{2}$. The presence of iron oxide has been confirmed by both XPS and XRD analysis. Parametric studies for the decoration procedure showed that the decoration density is proportional to the ratio of $\mathrm{CNT} / \mathrm{Fe}$ salt, without affecting particle size. The solvents used in the decoration steps affect the decorated CNT's morphology, decoration uniformity and decoration homogeneity. Methanol and ethanol were found to allow for a more uniform and homogenous decoration along the CNTs and also better powder morphology. On the other hand, DMF and acetone resulted in the formation of agglomeration islands on the CNTs and negatively affected the uniformity and homogeneity of decoration. The effect of the calcination period on the size of the decorating nanoclusters was studied as well. It was found that their size increases by increasing the calcination period. Regarding the gas sensing effect of the decoration, lower decoration density with higher particle size led to the best results.

The effect of the deposition method was also studied and was found to affect the behavior of the sensor. Namely, thinner, homogeneous, layered films obtained by airbrushing showed better response than thicker, non-homogeneous, layered sensors obtained by drop coating.

This last sensor deposited by air brushing showed an excellent selectivity for $\mathrm{NO}_{2}$ when carbon monoxide and benzene vapors were considered as potential interfering gases. Finally, the effect of humidity was studied. It was found that a more humid

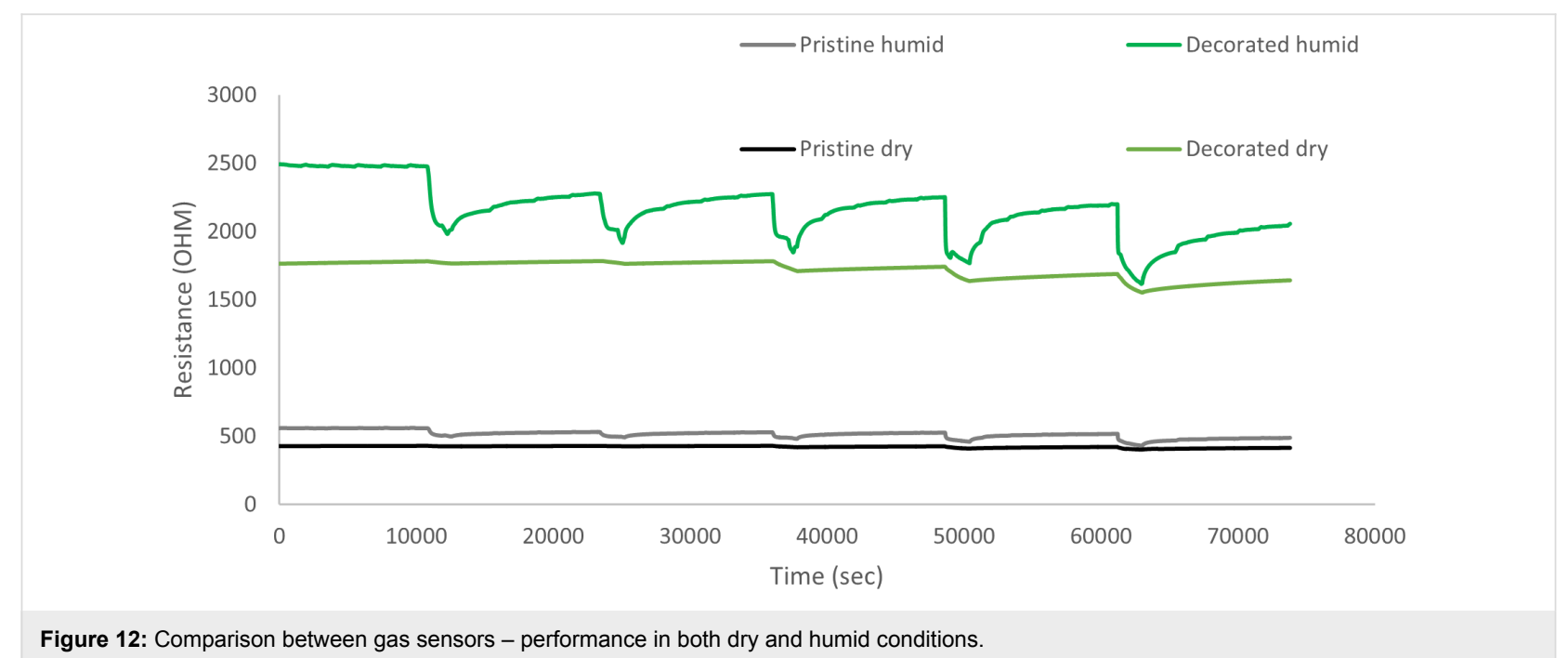

Figure 12: Comparison between gas sensors - performance in both dry and humid conditions. 
environment resulted in an increased and faster response of the sensor to $\mathrm{NO}_{2}$. This effect was observed for both pristine and decorated sensors.

\section{Supporting Information}

The supporting information features images of the effect of deposition technique on decorated carbon nanotubes, images of the wire bound sensor (both sides), images of the teflon gas sensing chamber, an image of the results from the first decoration method on carbon nanotubes, and a results showing the effect of the calcination period of the nanoparticle size.

\section{Supporting Information File 1}

Effect of deposition technique on decorated carbon nanotube morphology.

[https://www.beilstein-journals.org/bjnano/content/ supplementary/2190-4286-10-10-S1.pdf]

\section{Supporting Information File 2}

Wire bonded sensor.

[https://www.beilstein-journals.org/bjnano/content/ supplementary/2190-4286-10-10-S2.pdf]

\section{Supporting Information File 3}

Teflon gas sensing chamber allowing for 4 different sensors together for gas sensing.

[https://www.beilstein-journals.org/bjnano/content/ supplementary/2190-4286-10-10-S3.pdf]

\section{Supporting Information File 4}

Effect of first decoration step on carbon nanotube morphology.

[https://www.beilstein-journals.org/bjnano/content/ supplementary/2190-4286-10-10-S4.pdf]

\section{Supporting Information File 5}

Nanoparticle size distribution histograms.

[https://www.beilstein-journals.org/bjnano/content/ supplementary/2190-4286-10-10-S5.pdf]

\section{Acknowledgements}

This work has been funded in part by MINECO under grant no. TEC2015-71663-R, by the European Commission via the European Regional Development Fund (ERDF) and project XNEM 54833-TEMPUS-1-2013-1-EG-TEMPUS-JPCR and by the Catalan agency AGAUR under grant 2017SGR 418. Eduard Llobet is supported by the Catalan Institution for Research and Advanced Studies (ICREA) via the ICREA Academia Award.
MS is a FRS Postdoctoral Researcher, CB is Research Associate at the FRS-FNRS.

\section{Authors Contributions}

The chemical synthesis for the CNT decoration was performed by H. M. Elnabawy under the supervision of B. Anis, M. Fedawy, and A. S. G. Khalil. M. Scardamaglia and C. Bittencourt performed the XPS analysis. The preparation and characterization of the gas sensors was performed by H. M. Elnabawy and J. Casanova-Chafer under the supervision of E. Llobet and X. Vilanova. All the authors have collaborated in writing and revising the paper.

\section{Conflicts of Interest}

The authors declare no conflicts of interest. The founding sponsors had no role in the design of the study, in the collection, analyses, or interpretation of data, in the writing of the manuscript, or in the decision to publish the results.

\section{ORCID ${ }^{\circledR} \mathrm{iDs}$}

Juan Casanova-Chafer - https://orcid.org/0000-0002-3508-3462

Badawi Anis - https://orcid.org/0000-0002-7241-3088

Mostafa Fedawy - https://orcid.org/0000-0001-8556-1832

Mattia Scardamaglia - https://orcid.org/0000-0002-1128-7524

Eduard Llobet - https://orcid.org/0000-0001-6164-4342

Xavier Vilanova - https://orcid.org/0000-0002-6245-7933

\section{References}

1. lijima, S. Phys. B (Amsterdam, Neth.) 2002, 323, 1-5. doi:10.1016/s0921-4526(02)00869-4

2. Schönenberger, C.; Forró, L. Phys. World 2000, 13, 37-42. doi:10.1088/2058-7058/13/6/27

3. Kong, J.; Franklin, N. R.; Zhou, C.; Chapline, M. G.; Peng, S.; Cho, K.; Dai, H. Science 2000, 287, 622-625. doi:10.1126/science.287.5453.622

4. Wang, Y.; Yeow, J. T. W. J. Sens. 2009, 2009, No. 493904. doi:10.1155/2009/493904

5. Zaporotskova, I. V.; Boroznina, N. P.; Parkhomenko, Y. N.; Kozhitov, L. V. Mod. Electron. Mater. 2016, 2, 95-105. doi:10.1016/j.moem.2017.02.002

6. Abdelhalim, A.; Abdellah, A.; Scarpa, G.; Lugli, P. Nanotechnology 2014, 25, 055208. doi:10.1088/0957-4484/25/5/055208

7. Mudimela, P. R.; Scardamaglia, M.; González-León, O.; Reckinger, N.; Snyders, R.; Llobet, E.; Bittencourt, C.; Colomer, J.-F. Beilstein J. Nanotechnol. 2014, 5, 910-918. doi:10.3762/bjnano.5.104

8. Baccar, H.; Thamri, A.; Clément, P.; Llobet, E.; Abdelghani, A. Beilstein J. Nanotechnol. 2015, 6, 919-927. doi:10.3762/bjnano.6.95

9. Dilonardo, E.; Penza, M.; Alvisi, M.; Rossi, R.; Cassano, G.; Di Franco, C.; Palmisano, F.; Torsi, L.; Cioffi, N Beilstein J. Nanotechnol. 2017, 8, 592-603. doi:10.3762/bjnano.8.64

10. Zanolli, Z.; Leghrib, R.; Felten, A.; Pireaux, J.-J.; Llobet, E.; Charlier, J.-C. ACS Nano 2011, 5, 4592-4599. doi:10.1021/nn200294h 11. Peng, S.; Cho, K. Nano Lett. 2003, 3, 513-517. doi:10.1021/nl034064u 12. Liu, L.; Zhang, T.; Li, S. C.; Wang, L. Y.; Tian, Y. X. Chin. Sci. Bull. 2009, 54, 4371-4375. doi:10.1007/s11434-009-0662-9 
13. Lao, C. S.; Liu, J.; Gao, P.; Zhang, L.; Davidovic, D.; Tummala, R.; Wang, Z. L. Nano Lett. 2006, 6, 263-266. doi:10.1021/n1052239p

14. Cao, Y.; Luo, H.; Jia, D. Sens. Actuators, B 2013, 176, 618-624. doi:10.1016/j.snb.2012.10.067

15. Sun, P.; Wang, W.; Liu, Y.; Sun, Y.; Ma, J.; Lu, G. Sens. Actuators, B 2012, 173, 52-57. doi:10.1016/j.snb.2012.05.057

16. Mirzaei, A.; Hashemi, B.; Janghorban, K. J. Mater. Sci.: Mater. Electron. 2016, 27, 3109-3144. doi:10.1007/s10854-015-4200-z

17. Zhang, H.; Yu, L.; Li, Q.; Du, Y.; Ruan, S. Sens. Actuators, B 2017, 241, 109-115. doi:10.1016/j.snb.2016.10.059

18. Sonker, R. K.; Yadav, B. C. J. Taiwan Inst. Chem. Eng. 2017, 77, 276-281. doi:10.1016/j.jtice.2017.04.042

19. Tan, Q.; Fang, J.; Liu, W.; Xiong, J.; Zhang, W. Sensors 2015, 15, 28502-28512. doi:10.3390/s151128502

20. Tit, N.; Ezzi, M. M. A.; Abdullah, H. M.; Yusupov, M.; Kouser, S.; Bahlouli, H.; Yamani, Z. H. Mater. Chem. Phys. 2017, 186, 353-364. doi:10.1016/j.matchemphys.2016.11.006

21. Clément, P.; Hafaiedh, I.; Parra, E. J.; Thamri, A.; Guillot, J.; Abdelghani, A.; Llobet, E. Carbon 2014, 78, 510-520. doi:10.1016/j.carbon.2014.07.032

22. Pistone, A.; Piperno, A.; lannazzo, D.; Donato, N.; Latino, M.; Spadaro, D.; Neri, G. Sens. Actuators, B 2013, 186, 333-342. doi:10.1016/j.snb.2013.06.027

23. Hua, C.; Shang, Y.; Wang, Y.; Xu, J.; Zhang, Y.; Li, X.; Cao, A. Appl. Surf. Sci. 2017, 405, 405-411. doi:10.1016/j.apsusc.2017.01.301

24. Nitschke, M. Int. J. Environ. Health Res. 1999, 9, 39-53. doi:10.1080/09603129973344

25. Salvi, A.; Patki, G.; Liu, H.; Salim, S. Sci. Rep. 2017, 7, 8306. doi:10.1038/s41598-017-08859-1

26. Hou, P.-X.; Liu, C.; Cheng, H.-M. Carbon 2008, 46, 2003-2025. doi:10.1016/j.carbon.2008.09.009

27. Tsoufis, T.; Douvalis, A. P.; Lekka, C. E.; Trikalitis, P. N.; Bakas, T.; Gournis, D. J. Nanopart. Res. 2013, 15, 1924. doi:10.1007/s11051-013-1924-7

28. Aroutiounian, V. M. Lith. J. Phys. 2015, 55, 10. doi:10.3952/physics.v55i4.3230

29. Grosvenor, A. P.; Kobe, B. A.; Biesinger, M. C.; Mclntyre, N. S. Surf. Interface Anal. 2004, 36, 1564-1574. doi:10.1002/sia.1984

30. Gota, S.; Guiot, E.; Henriot, M.; Gautier-Soyer, M. Phys. Rev. B 1999, 60, 14387-14395. doi:10.1103/physrevb.60.14387

31. Biesinger, M. C.; Payne, B. P.; Grosvenor, A. P.; Lau, L. W. M.; Gerson, A. R.; Smart, R. S. C. Appl. Surf. Sci. 2011, 257, 2717-2730. doi:10.1016/j.apsusc.2010.10.051

32. Sahu, R. K.; Mukherjee, D.; Tiwari, J. P.; Mishra, T.; Roy, S. K.; Pathak, L. C. J. Mater. Chem. 2009, 19, 6810-6815. doi:10.1039/b908080e

33. Eltouny, N.; Ariya, P. A. Phys. Chem. Chem. Phys. 2014, 16, 23056-23066. doi:10.1039/c4cp02379j

34. Struzzi, C.; Scardamaglia, M.; Colomer, J.-F.; Verdini, A.; Floreano, L.; Snyders, R.; Bittencourt, C. Beilstein J. Nanotechnol. 2017, 8, 1723-1733. doi:10.3762/bjnano.8.173

35. Roso, S.; Degler, D.; Llobet, E.; Barsan, N.; Urakawa, A. ACS Sens. 2017, 2, 1272-1277. doi:10.1021/acssensors.7b00504

36. Lee, Y.-C.; Chueh, Y.-L.; Hsieh, C.-H.; Chang, M.-T.; Chou, L.-J.; Wang, Z. L.; Lan, Y.-W.; Chen, C.-D.; Kurata, H.; Isoda, S. Small 2007, 3, 1356-1361. doi:10.1002/smll.200700004

\section{License and Terms}

This is an Open Access article under the terms of the Creative Commons Attribution License (http://creativecommons.org/licenses/by/4.0). Please note that the reuse, redistribution and reproduction in particular requires that the authors and source are credited.

The license is subject to the Beilstein Journal of Nanotechnology terms and conditions: (https://www.beilstein-journals.org/bjnano)

The definitive version of this article is the electronic one which can be found at:

doi:10.3762/bjnano.10.10 